\title{
Alquiler de viviendas en asentamientos populares consolidados de Lima. Un acercamiento a la información oficial y a las preferencias locacionales de la demanda ${ }^{+}$
}

\author{
ANDERSON ALEXIS GARCÍA CRISTÓBAL* \\ Universidad Nacional Mayor de San Marcos \\ agarciacristobal@gmail.com \\ https://doi.org/108800/rcpg.201801.001
}

\section{Resumen}

Este artículo es una aproximación cuantitativa y cualitativa a los alquileres residenciales en los asentamientos populares consolidados de Lima. A partir de los datos oficiales se muestra un aumento significativo de la tenencia en alquiler tanto en términos absolutos como relativos. Asimismo, se señala que no existen mayores diferencias, respecto a la calidad habitacional, entre las viviendas en alquiler en asentamientos consolidados y las viviendas propias sin título de propiedad en asentamientos no consolidados, por lo cual el aumento del alquiler debe explicarse por las preferencias locacionales de la demanda. Se plantea que dichas preferencias tienen en cuenta que el barrio goce de una buena accesibilidad (en tiempo y distancia) a los puestos de trabajo y cuente con servicios locales. Además, el alquiler ofrece una forma particular de seguridad de la tenencia, que el aumento de los mecanismos delictivos del mercado de loteos ya no garantiza.

Palabras clave: mercado de suelo, mercado informal de alquileres, asentamientos irregulares consolidados, preferencias locacionales, política de vivienda.

+ Recibido el 19 de abril de 2018; aceptado el 04 de diciembre de 2018.

* Máster en Sociología de la Población y el Territorio por la Universidad Complutense de Madrid (Espańa). Miembro del Grupo de Trabajo Informalidades Urbanas (IFEA). 


\title{
Rental housing in Lima's consolidated popular settlements. An approach o the official data and to location preferences
}

\begin{abstract}
This paper develops a quantitative and qualitative approach to residential rents in Lima's consolidated popular settlements. Through the use of official data we show a significant increase in tenure for rent both in absolute and relative terms. Also, it is noted that there are no major differences, with respect to housing quality, between rental housing in consolidated settlements and self-owned houses without property title in unconsolidated settlements. We explain the rent increase in reference to demand's location preferences. These preferences take into account that the neighborhood enjoys good accessibility (in time and distance) to jobs and has local services. In addition, the rent offers a particular form of security of tenure, which the increase of criminal practices such as the informal selling of land no longer guarantees.
\end{abstract}

Keywords: land market, informal rental market, consolidated settlements, location preferences, housing policy. 


\section{INTRODUCCIÓN}

La investigación urbana en América Latina ha llegado a un consenso sobre la necesidad de políticas preventivas — antes que curativas - para limitar el crecimiento informal e ilegal de nuestras ciudades. Dicho consenso propone soluciones como el acceso ordenado al suelo urbano servido y la promoción de la vivienda social en propiedad. Para el caso peruano, esta última es la más importante opción habitacional de la política de vivienda social desde 2002, año en que se crea el Programa Techo Propio.

Sin embargo, la importancia dada a la vivienda en propiedad no ha permitido indagar en otras soluciones habitacionales como la vivienda en alquiler, a fin de incluirla en las políticas habitacionales para la ciudad autoconstruida. Hacer esta indagación se torna necesaria cuando este tipo de tenencia, en los asentamientos consolidados de Lima, ha mostrado un aumento significativo desde 1993, conformando un submercado de alquileres (tal como viene sucediendo en otras ciudades de América Latina).

En este sentido, el presente artículo es una aproximación a la vivienda en alquiler en dichos asentamientos, a fin de generar una discusión teórica acerca de las preferencias locacionales de sus residentes. La línea argumentativa es que el alquiler en los distritos con asentamientos consolidados se ha convertido en una modalidad de acceso al suelo en aumento; y esto se debe a que las preferencias locacionales y residenciales de los hogares vienen privilegiando, antes que la vivienda como tal, una mejor localización, los beneficios de la accesibilidad local y una forma particular de seguridad de la tenencia.

Asimismo, teniendo en cuenta el fracaso de la regularización de la tenencia en la prevención de la informalidad ${ }^{1}$ y ante el poco éxito de la vivienda social nueva, este estudio busca reflexionar ante la pregunta: ‘acaso la vivienda en alquiler en asentamientos irregulares consolidados tiene el potencial de convertirse en una solución viable de política pública para atender las necesidades habitacionales de los sectores de menores ingresos?

\footnotetext{
Como ha señalado Fernandes (2011) en un estudio sobre las experiencias de regularización de la tenencia en Perú y Brasil, a pesar de tener dos enfoques diferentes, comparten el hecho de no afrontar la naturaleza y las causas del desarrollo informal. Al concebirse al margen de políticas fiscales, de vivienda y urbanas, han generado algunas consecuencias imprevistas, entre las que destacan: el impacto sobre los mercados de suelo informales, la formalización de asentamientos no sustentables, gentrificación (sobre todo en barrios ubicados en los centros urbanos), manipulación política de los programas de titulación, y problemas con el registro de nuevos títulos del suelo. Sin embargo, una de las críticas más importantes a la regularización es que fomentan nuevos asentamientos informales con la expectativa de que se legalizarán en el futuro.
} 


\section{LA INVESTIGACIÓN SOBRE ASENTAMIENTOS CONSOLIDADOS Y TENENCIA EN ALQUILER EN CIUDADES DE AMÉRICA LATINA Y LIMA}

\subsection{Asentamientos consolidados en América Latina y Lima}

Se denominan «asentamientos populares consolidados» (Abramo, 2012), «asentamientos irregulares consolidados» — $\mathrm{O}$ «innerburbs» (palabra del inglés compuesta por inner suburbs) — a las áreas consolidadas que conforman una corona intermedia entre la ciudad histórica y la periferia reciente (Ward, Jiménez y Di Virgilio, 2015).

Dichos asentamientos fueron objeto de las políticas de mejoramiento urbano de primera y segunda generación, aplicadas en la región desde la década de 1970 (Ward, Jiménez y Di Virgilio, 2015). Sin embargo, en la actualidad han suscitado un creciente interés y preocupación pues poseen un stock de viviendas sobre las que existen dudas acerca de su calidad constructiva (al haber sido edificadas sin asistencia técnica), por lo que algunos investigadores, como Ward, han señalado la necesidad de una tercera política de vivienda, centrada en la rehabilitación urbana de estos asentamientos.

Para el caso de Lima, por ejemplo, Calderón (2011) apunta otros dos problemas habitacionales de los asentamientos consolidados: el tugurio y el hacinamiento. Para este autor, «la dinámica de densificación en la ciudad popular está generando la emergencia de un tipo de tugurio que ya debería ser regulado por las autoridades» (p. 59).

Lamentablemente, el concepto de «barrio urbano marginal»" empleado por el Ministerio de Vivienda, Construcción y Saneamiento, no permite distinguir entre asentamientos informales recientes — cuya precariedad se debe a su carencia de servicios por ser relativamente nuevos- y asentamientos consolidados —aquellos que ya cuentan con servicios básicos y cuyos problemas habitacionales derivarían de su antigüedad y procesos de deterioro-.

\subsection{La investigación sobre alquileres en asentamientos consolidados de América Latina}

En la investigación urbana latinoamericana, otra de las razones que ha motivado el estudio de los asentamientos consolidados ha sido la emergencia del submercado informal de alquileres, tanto residenciales como comerciales.

\footnotetext{
2 Se denomina como «barrio urbano marginal» (BUM) a todo «núcleo urbano caracterizado por presentar altos niveles de pobreza monetaria y no monetaria y carecer, total o parcialmente, de servicios de infraestructura y de servicios de equipamiento» (Ministerio de Vivienda, Construcción y Saneamiento, 2014).
} 
Es necesario precisar que lo informal no designa una categorización espacial (zonas formales versus zonas informales), sino una forma particular de práctica productora de ciudad cuyo valor es negociable (McFarlane, 2012). Por ello, el término "submercado informal», antes que hacer alusión a un territorio, define un conjunto de relaciones sociales y económicas, es decir, prácticas en las cuales los bienes que se negocian «no están regulados por los organismos públicos jurídicos (registro de inmuebles) ni administrativos (administraciones locales y federales)»(Abramo, 2005). Esto no significa que no existan reglas de funcionamiento, sino que dichas reglas se sujetan, antes que a una «regulación política», a una «regulación social» (Lascoumes y Le Galès, 2014).

Es Abramo quien más ha aportado a la comprensión de las características del mercado informal del suelo, del cual el submercado de alquileres es parte. Dicho autor señala al menos tres características de este submercado: a) que la oferta de alquiler informal es la resultante de fraccionamientos o extensiones de unidades residenciales o subdivisión de lotes construidos, b) que existe un predominio de pequeñas unidades habitacionales que alimenta la compactación informal, y c) que las ganancias mediante la oferta de alquiler estimula a las familias propietarias a fraccionar sus unidades habitacionales (Abramo, 2012).

Por otro lado, la investigadora colombiana Parias (2010) planteó lo siguiente: ¿por qué, ante el importante papel que cumple la propiedad del suelo y el costo de alquiler elevado, importantes sectores populares deciden arrendar? Para ella es importante analizar las «estrategias residenciales» de los arrendatarios.

De esta manera, tomando como caso de estudio los barrios informales de Bogotá, la autora señala que las decisiones residenciales son territorializadas y que los arrendatarios toman sus «decisiones residenciales» sobre la base de una «racionalidad estratégica» (p. 78). Esta autora apunta que existen tres razones por las que el acceso a la vivienda en propiedad no parece ser una opción atractiva para los arrendatarios: a) los barrios consolidados gozan de una mejor posición en la jerarquía socioespacial que los lotes de la periferia, b) el proceso de autoconstrucción requiere de conocimiento, disponibilidad de mano de obra y ahorros, que no reúnen los hogares, y c) el mercado de loteos no ofrece externalidades de proximidad, pues estas se construyen a lo largo del tiempo (p. 99).

Finalmente, Briceño (2010), para el caso de Caracas, señala que el mercado informal de viviendas en alquiler es el más dinámico en Venezuela por dos factores: a) la inexistencia de una producción de vivienda para la venta y b) la libertad para alquilar en los asentamientos informales. Para este autor la libertad para alquilar es el resultado de la «libertad para» construir de los sectores pobres, concepto popularizado por John F. C. Turner en la década de 1960. 
De esta manera, son «los habitantes de los barrios quienes se han transformado en los pequeños empresarios de la vivienda de alquiler, en un sector privado dinámico que está respondiendo a las señales del mercado con sus propios mecanismos y reglas» (Briceño, 2010, p. 124).

Este repaso de tres de las investigaciones relativamente recientes sobre viviendas en alquiler revela que existe un esfuerzo importante por establecer la relación entre el funcionamiento del submercado de alquiler y su impacto en la compactación de la estructura urbana (Abramo, 2012), comprender las preferencias locacionales de la demanda a partir de las decisiones residenciales (Parias, 2010) y comprender las lógicas de los propietarios que motivan la oferta de viviendas en alquiler (Briceño, 2010).

\subsection{La investigación sobre alquileres en asentamientos consolidados de Lima}

Para el caso limeño, los estudios sobre la ciudad autoconstruida no han abordado como tema principal la tenencia en alquiler, habiendo recibido apenas algunas menciones tangenciales (Burga, 2006; Riofrío y Driant, 1987; Zolezzi, Tokeshi y Noriega, 2005).

Cabe mencionar el estudio de Riofrío y Driant (1987), pues plantean como hipótesis de trabajo que el proceso de edificación de viviendas terminaría produciendo un parque de viviendas que serían ofertadas en alquiler, conformando un mercado popular de viviendas en las barriadas. Sin embargo, de acuerdo a sus resultados de análisis en los barrios investigados, los cuales datan de las décadas de 1950 y 1960, dicha hipótesis no pudo ser comprobada.

Dichos autores señalaron que existe una mayor presencia de «alojados» — por lo general hijos de los propietarios que presionan por tener una pieza residencial en la misma edificación- que presencia de inquilinato, aún en estado incipiente. En efecto, para el año de la investigación (1984), las barriadas originadas en la década de 1960 tenían "poca capacidad para producir habitaciones extra que puedan ser ofrecidas a gente extraña en alquiler» (Riofrío y Driant, 1987, p. 99).

Por otro lado, una excepción a la ausencia de estudios sobre viviendas en alquiler han sido las investigaciones sobre el mercado inmobiliario informal elaboradas por Calderón $(2007,2011)$, dos de las cuales merecen una especial revisión.

A partir de una encuesta aplicada en cinco barriadas de Lima, Calderón (2007) señala que en los llamados «sectores populares» existe un proceso de diferenciación social, canalizado mediante el «acceso secundario al suelo» por los «mercados inmobiliarios en asentamientos consolidados» (MIAI). 
Los MIAI establecen una gradiente de precios para quienes pueden evadir el "costo de invasión», siendo que el precio más bajo se encuentra en las zonas en proceso de consolidación y de ocupación reciente. En el otro lado de la gradiente de precios, los más altos se encuentran en los asentamientos consolidados, aunque dicho precio tiene un tope de crecimiento debido al estigma social de vivir en un "pueblo joven».

Dicha diferenciación brindaría a los diversos estratos sociales un abanico de posibilidades de movilidad residencial, dentro de las cuales se encuentra el alquiler en zonas consolidadas y no consolidas. Para el autor, los inquilinos "prefieren pagar un alquiler debido a que sus recursos les permiten evadir el costo de la invasión» (Calderón, 2007, p. 18). Asimismo, Calderón considera que el MIAI está permitiendo también a los inquilinos convertirse en propietarios, mediante la compra de lotes.

Calderón también analiza la relación entre la tenencia de títulos de propiedad y los mercados inmobiliarios en cinco asentamientos de origen informal y/o ilegal, tres en San Juan de Lurigancho, uno en Villa El Salvador y uno en Ate (Calderón, 2011). El autor señala que en los asentamientos consolidados predomina el mercado de alquileres, mientras que en los asentamientos no consolidados predomina la compra y venta de lotes.

Asimismo, en los asentamientos consolidados (Sector 1 de Villa El Salvador, Huáscar B y Huáscar C) los inquilinos están dispuestos a pagar más por ventajas de localización y son indiferentes a si el barrio cuenta o no con título de propiedad (2011, p. 60). En cambio, el título tiene mayor importancia en los asentamientos no consolidados, ya que un lote con título costaba 2,6 veces más en Ampliación Huáscar, en San Juan de Lurigancho y en Zona Alta de Huaycán, en Ate.

Finalmente, el autor concluye que la política de titulación no está conduciendo a los agentes económicos a los mercados inmobiliarios informales, por el contrario, están recreando la informalidad. Para el caso de los alquileres, por ejemplo, los arrendadores de cuartos no declaran los ingresos derivados de estos a fin de no reducir su rentabilidad. Asimismo, el autor llama la atención que los barrios consolidados «acogen modalidades de alquiler de verdaderos tugurios» (2011, p. 73).

Pese al aporte de estas investigaciones, hace falta una mirada global de la situación del alquiler en el conjunto de los asentamientos consolidados sobre la base de información oficial (censos y encuestas), y no ya a partir de unos pocos casos de estudio. Asimismo, se advierte la necesidad de un ejercicio 
comprensivo acerca de las motivaciones de la demanda para decantarse por la vivienda en alquiler en estos asentamientos.

\subsection{Justificación del estudio}

Excluyendo los estudios de caso de Calderón, estamos ante un fenómeno novedoso y poco estudiado en Lima. Por eso, el presente artículo parte de la premisa que el estudio de los alquileres residenciales en asentamientos consolidados es de interés a la investigación urbana peruana por dos motivos: a) porque cuestiona a «la barriada» como paradigma de interpretación de la ciudad autoconstruida ${ }^{3}$, y b) porque permite ahondar en la comprensión de las formas de mercantilización del acceso al suelo ${ }^{4}$ en América Latina, proceso del cual Lima no es ajena.

Como señala Jiménez, «mientras la problemática de los asentamientos irregulares de reciente creación sí se conoce y existen esfuerzos mundiales que aunque modestos, buscan formas para remediarla, esto no sucede con los asentamientos irregulares consolidados» ${ }^{5}$ (2014, p. 21).

\section{MÉTOdo, CRITERIOS Y ALCANCES DEL ESTUdio}

Este artículo es una aproximación cuantitativa y cualitativa al mercado informal de alquileres residenciales en los asentamientos populares consolidados de Lima. A fin de determinar el universo de lotes en asentamientos consolidados nos hemos basado en la propuesta de identificación de barrios urbanos vulnerables (BUV) de Espinoza y Fort (2017), seleccionando trece de los quince distritos con mayor concentración de estos barrios de la provincia de Lima ${ }^{6}$.

\footnotetext{
3 Se define a la «barriada» como una modalidad no mercantil de acceso al suelo, donde este se toma o se ocupa, antes que se compre o se alquile (Calderón, 2016).

4 La modalidad «no mercantil» de acceso al suelo ha dejado de ser la regla en Lima, el acceso al suelo viene mercantilizándose, no solo por la vía del alquiler sino por la compra y venta de lotes. Esta última, por ejemplo, ha llegado a configurar una práctica llamada «tráfico de terrenos», la misma que ha tornado difusa la frontera entre la economía formal y la delictiva. El fenómeno del tráfico de terrenos y el mercado de loteos viene siendo estudiado por el Grupo de Investigación Informalidades Urbanas (IFEA), que ya ha presentado, en reuniones de trabajo, los resultados de las investigaciones inéditas de Julio Calderón, Nekson Pimentel y Jimena Niquen.

5 En el presente artículo mantendremos el término «asentamientos irregulares consolidados». Sin embargo, el término "consolidación» debería ser problematizado ya que solo hace alusión a los asentamientos que cuentan con servicios básicos, invisibilizando procesos de deterioro y obsolescencia.

6 Estos distritos son: San Juan de Lurigancho, San Martín de Porres, Comas, Ate, Villa El Salvador, Villa María del Triunfo, San Juan de Miraflores, Los Olivos, Chorrillos, Carabayllo, Puente Piedra, Independencia. No se consideraron Lima ni Rímac, por ser distritos ubicados en la zona central de la ciudad. Todos estos distritos tienen asentamientos irregulares consolidados, fundados entre 1945 y 1990 , es decir que cuentan con más de 25 años de antigüedad.
} 
Se optó por elegir a los BUV como criterio de selección para los asentamientos consolidados, ya que permite construir una lógica relacional del territorio pues, pese a ser escenarios de dos submercados de suelo (de loteos y de alquileres, respectivamente), se retroalimentan y configuran una estructura urbana difusa en los bordes urbanos y compacta en las áreas consolidadas (Abramo, 2012).

En atención a dichos distritos se reprocesó la base de datos de barrios y asentamientos del Organismo de Formalización de la Propiedad Informal (Cofopri), a fin de contar con un plano de los asentamientos fundados entre 1951 y 1989 , la misma que sirvió para sobreponerla a las bases de datos georreferenciadas de los Censos del Instituto Nacional de Informática (INEI) de 1993 y 2007, a nivel de manzana. Esto nos ha permitido contar con información precisa para el estudio de la evolución intercensal del alquiler y determinar su peso relativo respecto al total de los tipos de tenencia, para ambos censos.

Por otra parte, para evaluar el estado del alquiler actual y la evolución de su precio se ha realizado un tratamiento estadístico con el software SPSS a los microdatos de la Encuesta Nacional de Hogares (Enaho) anual actualizada desde 2008 hasta 2016.

En la parte final del artículo, de aproximación cualitativa, se presenta una discusión teórica en torno a las "preferencias locacionales de la demanda», sobre la base de dos entrevistas semiestructuradas de una investigación en curso. Estas se han tomado a manera de casos de estudio y en atención a los aportes metodológicos de Becker (2016).

Este autor considera que en la investigación sociológica los estudios de casos deben permitir discusiones que alimenten razonamientos teóricos (p. 71), para lo cual cada caso debe permitir la búsqueda de nuevas dimensiones de explicación de los fenómenos.

En ese sentido, se advierte que la finalidad de la parte cualitativa del presente texto no es generar conclusiones representativas, sino proponer reflexiones y nuevas preguntas, a fin de aportar a la construcción de una agenda de investigación para un tema poco visible en la investigación urbana sobre la ciudad de Lima. 


\section{Plano 1. Asentamientos consolidados de Lima (1950-1989)}

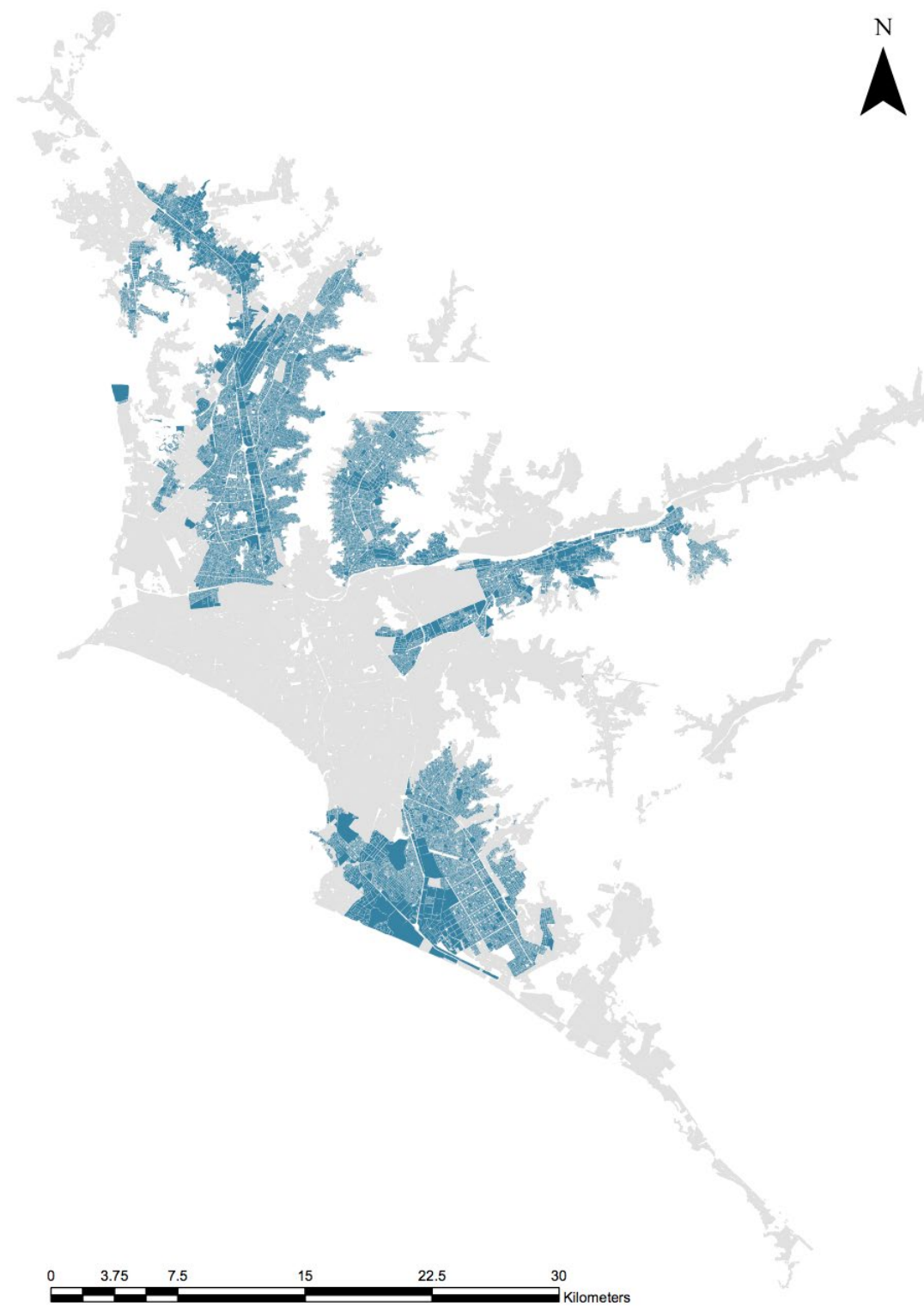

Fuente: INEI-Censos Nacionales 2007: XI de población y VI de vivienda. Base de datos georreferenciada. Elaboración del autor. 


\section{EVOLUCIÓN, CARACTERÍSTICAS Y PRECIOS DEL ALQUILER ENASENTAMIENTOS IRREGULARES CONSOLIDADOS DE LIMA}

\subsection{Cuantificación y evolución de las viviendas en alquiler}

En Lima, los asentamientos consolidados (fundados entre 1951 y 1989) se ubican en dirección norte, sur y este de la ciudad. Al año 2007 esta área de la ciudad tenía un total de 850620 viviendas, de las cuales 161717 estaban en alquiler, lo cual representa $19 \%$ del total de tenencia en los asentamientos consolidados.

Gráfico 1. Asentamientos consolidados de Lima: porcentaje de viviendas por tipo de tenencia, 2007

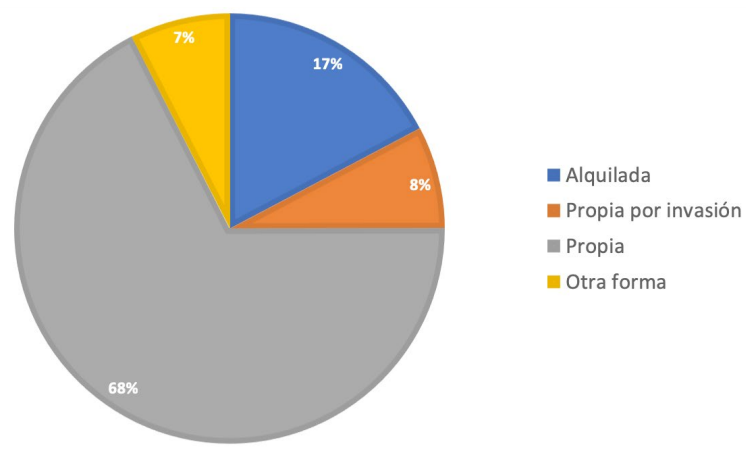

Fuente: INEI-Censos Nacionales 2007: XI de población y VI de vivienda. Base de datos georreferenciada. Elaboración del autor.

Es importante señalar el incremento significativo de los alquileres respecto a 1993, ya que para dicho año solo existían 48402 viviendas alquiladas, representando un incremento del $243 \%$, una tasa de crecimiento mayor que la del parque total de viviendas en asentamientos consolidados, que se vio incrementado en 250815 unidades, con una tasa de crecimiento del $42 \%$.

Asimismo, hay que destacar la evolución intercensal de las viviendas sin título de propiedad, que para el año 2007 apenas representaba el 5\%, con una tasa de crecimiento intercensal negativa de $-43 \%$; lo cual se condice con las políticas de formalización de la propiedad aplicados durante la década de 1990 .

Se debe señalar también que el incremento de las viviendas propias totalmente pagadas y pagadas a plazos, el tipo de tenencia de mayor crecimiento en términos absolutos, responde tanto al traspase de las viviendas sin título de propiedad a dicha categoría, así como al proceso de densificación en asentamientos consolidados. 
Tabla 1. Asentamientos consolidados de Lima: comparación de tipos de tenencia entre Censos 1993 y 2007

\begin{tabular}{lccccc}
\hline & Alquilada & $\begin{array}{c}\text { Propia sin } \\
\text { título de } \\
\text { propiedad }\end{array}$ & $\begin{array}{c}\text { Propia totalmente } \\
\text { pagada y pagada a } \\
\text { plazos }\end{array}$ & $\begin{array}{c}\text { Otra } \\
\text { forma }\end{array}$ & $\begin{array}{c}\text { Total de } \\
\text { viviendas }\end{array}$ \\
\hline Número de viviendas 1993 & 48402 & 76032 & 410629 & 64742 & 599805 \\
Número de viviendas 2007 & 161717 & 43028 & 582978 & 62897 & 850620 \\
Incremento de viviendas & 113315 & -33004 & 172349 & -1845 & 250815 \\
Tasa de crecimiento & $234 \%$ & $-43 \%$ & $42 \%$ & $-3 \%$ & $42 \%$ \\
\hline
\end{tabular}

Fuente: INEI-Censos Nacionales 1993 y 2007. Base de datos georreferenciada. Elaboración del autor.

Si analizamos los datos del Censo 2007 por distrito, encontramos que la proporción de viviendas en alquiler no es uniforme en todos los asentamientos consolidados. Por ejemplo, en los asentamientos consolidados de Carabayllo, Villa María del Triunfo, Puente Piedra y Villa El Salvador, las viviendas alquiladas representaban apenas el 10\%, muy por debajo del promedio general.

Tabla 2. Clasificación de distritos con asentamientos consolidados, según nivel de alquiler de viviendas

\begin{tabular}{lcc}
\hline Distritos & \% de vivienda alquilada & Rango \\
\hline Carabayllo & $10 \%$ & \\
Villa María del Triunfo & $10 \%$ & Alquiler bajo \\
Puente Piedra & $10 \%$ & $1 \%-10 \%$ \\
Villa El Salvador & $10 \%$ & \\
\hline San Juan de Miraflores & $14 \%$ & \\
Comas & $16 \%$ & Alquiler medio \\
Independencia & $18 \%$ & $11 \%-20 \%$ \\
San Juan de Lurigancho & $20 \%$ & \\
\hline Chorrillos & $21 \%$ & \\
Ate & $25 \%$ & Alquiler alto \\
San Martín de Porres & $27 \%$ & \\
Los Olivos & $30 \%$ & $30 \%$ \\
\hline
\end{tabular}

Fuente: INEI-Censos Nacionales 2007: XI de población y VI de vivienda. Base de datos georreferenciada. Elaboración del autor.

Una explicación a este bajo porcentaje la podríamos encontrar en la disponibilidad de terrenos vacantes que aún presentan dichos distritos, ya que 
sus manchas urbanas no han consumido todas sus extensiones jurisdiccionales, con la excepción de Villa El Salvador. En efecto, si tomamos los datos del Censo 2007 para la totalidad de dichos distritos (no solo de sus asentamientos consolidados), se puede apreciar que estos presentan los mayores porcentajes de viviendas propias sin título de propiedad.

En el otro polo se encuentran los asentamientos consolidados de Los Olivos, San Martín y Ate, con los mayores porcentajes de alquiler (30\%, 27\% y 25\%, respectivamente). Para los dos primeros también podría aplicarse la hipótesis de la poca disponibilidad de terrenos vacantes, razón por la cual presentan porcentajes de viviendas sin título de propiedad por debajo del $5 \%$.

En este grupo cabe resaltar la situación de Ate, ya que este distrito sí presenta zonas baldías que podrían, en teoría, ser ocupadas mediante loteos informales. Desde luego, siempre existe la posibilidad que existan zonas de muy alta pendiente que hagan casi imposible la ocupación humana. Sin embargo, es necesario considerar también la hipótesis del fenómeno de las superperiferias.

Para Abramo (2012), dicho fenómeno ocurre en las ciudades de gran crecimiento horizontal, en donde a pesar de existir terrenos disponibles, las nuevas familias satisfarían su necesidad de vivienda en áreas menos alejadas, mediante el mercado informal de alquileres, que aseguraría precios comparativamente menores frente al mercado formal.

De esta manera, alquilar una vivienda en un asentamiento consolidado permitiría ahorrar tiempo y dinero destinado a transporte. Se trata de una hipótesis que debería corroborarse en futuras investigaciones.

Finalmente, hemos elaborado un mapa de las manzanas con más viviendas en alquileres. Como se puede observar en el Plano 2, la zona sur de Lima presenta los menores niveles, mientras que existe una distribución más o menos homogénea entre Lima Norte, San Juan de Lurigancho y Ate. Asimismo, se advierten un patrón de ubicación de las viviendas alquiladas ya que las manzanas con mayor presencia de este tipo de viviendas se localizan en áreas más cercanas a la zona central de la ciudad.

Otro elemento a tener en cuenta es la presencia de centralidades de empleo. En efecto, si consideramos los resultados de la investigación de Gonzales de Olarte (2012), quien identificó los diez principales subcentros de Lima, excluyendo los seis que se encuentran en la zona central de la ciudad, los cuatro restantes se ubican en los asentamientos consolidados de San Juan de Lurigancho (Zárate), Ate, Los Olivos y Chorrillos, y coinciden con la presencia de las manzanas con más viviendas en alquiler (las de color azul intenso en el Plano 2). 
Plano 2. Asentamientos consolidados de Lima: localización de manzanas según número de viviendas en alquiler

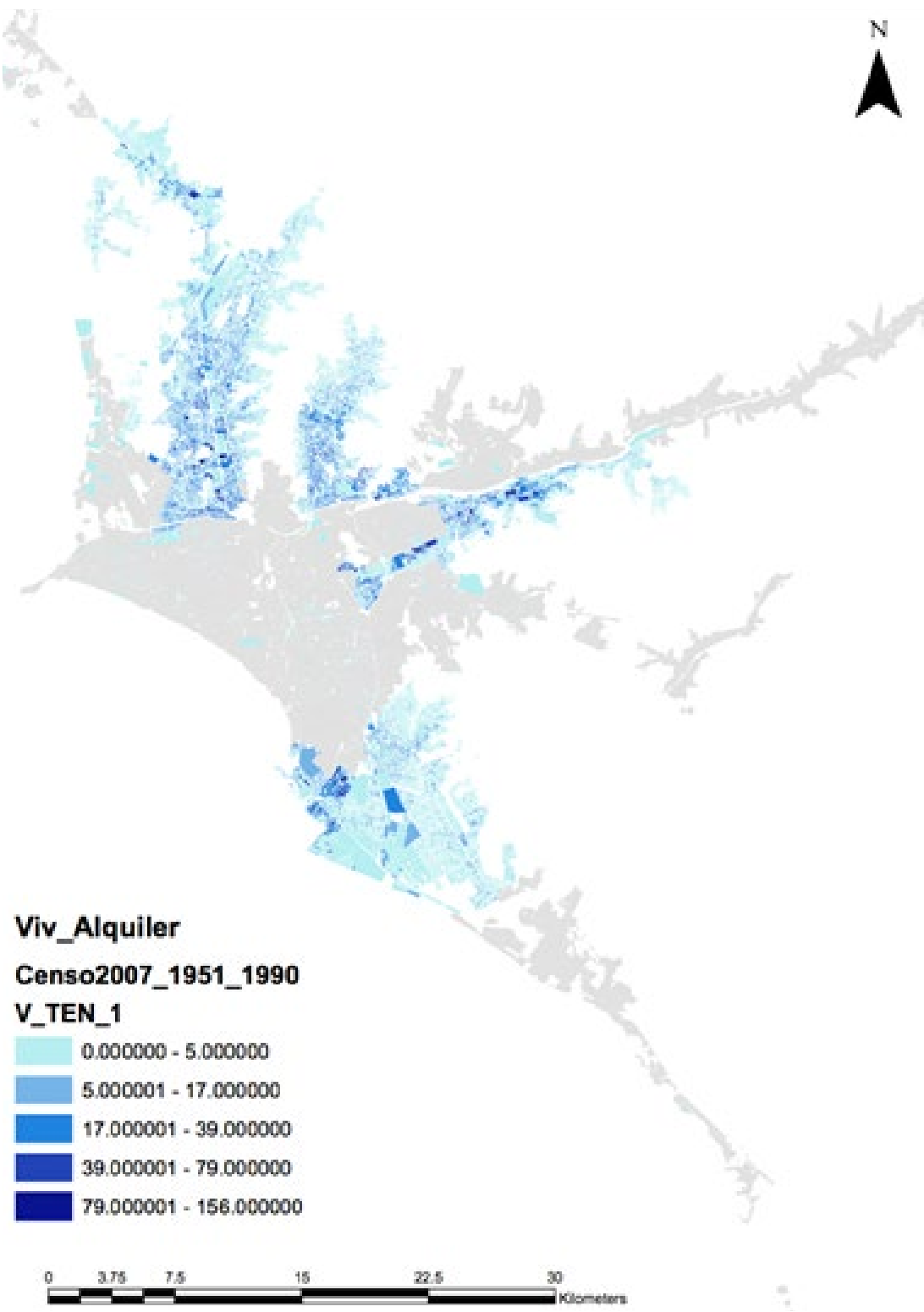

Fuente: INEI-Censos Nacionales 2007: XI de población y VI de vivienda. Base de datos georreferenciada. Elaboración del autor. 


\subsection{Características de la vivienda alquilada}

Un avance en los estudios contemporáneos sobre la vivienda ha sido superar la relación primaria entre hogar y vivienda (home studies) para dar paso a una sociología de la residencia, que pone en relación —a manera de cajas chinasel hogar-la vivienda-la localidad-y la estructura social (Kemeny, 1992). Sin embargo, este esfuerzo de teorización no permite comprender otros aspectos más sutiles, como las trayectorias y las estrategias residenciales (Artacho, 2014, p. 37). Y tampoco da cuenta de las preferencias locacionales o residenciales.

Por esto, antes de pasar a entender los aspectos cualitativos de la demanda del alquiler, es necesario revisar las condiciones físicas del bien transable. Para ello, repasaremos los datos de la Enaho 2016 (anual) que nos permitan un acercamiento a las condiciones físicas de las viviendas alquiladas, a partir de tres variables: cantidad de habitaciones, condición de hacinamiento y calidad de la vivienda.

Es necesario señalar que los microdatos de la Enaho no son georreferenciados, por lo cual son representativos solo a nivel de distritos. Sin embargo, para este análisis consideramos que las «viviendas alquiladas» son representativas de los asentamientos consolidados, mientras que las «viviendas propias por invasión", entiéndase las viviendas sin título de propiedad (de acuerdo a la definición del INEI), son representativas de los asentamientos no consolidados. Para esta evaluación hemos seleccionado a los trece distritos con mayor concentración de barrios urbanos vulnerables, en adelante distritos BUV 13.

Respecto al tipo de vivienda, hemos comparado la distribución de las viviendas alquiladas con el promedio de los distritos BUV 13. Para esto es necesario aclarar que de acuerdo a la Ficha Técnica Enaho 2016, la población objetivo está conformada por el conjunto de viviendas particulares y sus ocupantes residentes. Asimismo, se debe precisar que las viviendas particulares pueden estar conformadas tanto por una habitación o un conjunto de habitaciones. En ese sentido, los cálculos realizados para esta investigación señalan que existe predominancia de la casa independiente (62\%) frente al departamento en edificio (36\%).

Aunque dicha encuesta considera los tipos de vivienda, no cuenta en su ficha técnica con una definición para "casa independiente» ni "departamento en edificio». Sin embargo, el INEI sí las incluye en sus definiciones como parte de su anexo de conceptos censales, de allí que, asumiendo que dichas definiciones no son diferentes para censo y encuesta, es necesario considerar que las casas independientes constituyen una sola vivienda y son edificaciones con salida directa a la calle; mientras que el departamento en edificio es toda vivienda que formando parte de un edificio de más de un piso tiene acceso indirecto a la vía pública, considerando en este grupo a aquellas viviendas del primer piso de la edificación. 
Gráfico 2. Distritos BUV 13: Tipo de vivienda por tipo de tenencia, 2016

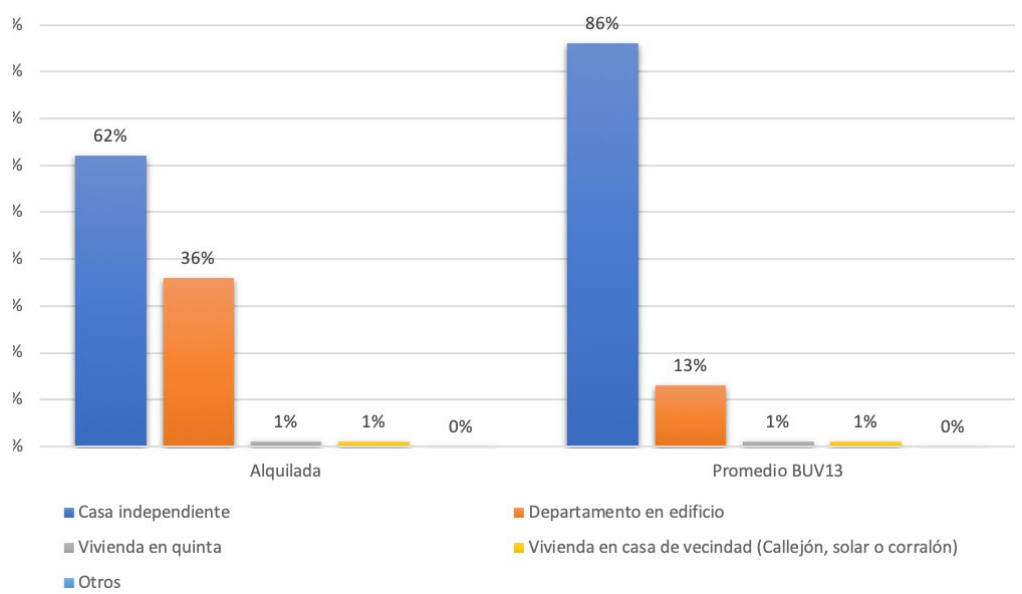

Fuente: INEI-ENAHO Anual 2016. Elaboración del autor.

Esta aclaración es relevante porque permite dar cuenta que las preferencias residenciales de los inquilinos se decantan por la vivienda tipo chalet, y hace tomar con cautela la relación entre alquileres y densificación habitacional. Mientras que la segunda ha sido definida como el proceso de agregación de nuevas unidades de vivienda en áreas del mismo lote, o en los aires, a fin de convertir viviendas unifamiliares en bi o trifamiliares (Zolezzi, Tokeshi y Noriega, 2005), la primera, es decir el alquiler, muestra indicios de ser fundamentalmente unifamiliar.

Asimismo, por el lado de la oferta, los datos permiten sugerir una apreciación sobre la lógica de los arrendadores, ya que al tener predominancia la «casa independiente», se puede inferir que los arrendadores estarían más cercanos al «alquiler mercantil progresivo» (Briceño, 2010), es decir un arrendador que no vive en la misma edificación que el arrendatario y cuya operación inmobiliaria (alquiler) está motivada por la rentabilidad de una inversión de capital.

Por el contrario, el «alquiler doméstico» describe a un arrendador que vive en la misma edificación y donde la operación inmobiliaria tiene la lógica del «ingreso extra» (Briceño, 2010). Cabe mencionar que «alquiler doméstico» es el común denominador en el mercado informal de alquileres de Bogotá y Caracas, lo cual pondría a Lima como una excepción en los mercados de alquileres en asentamientos consolidados de América Latina.

Por otro lado, si se analiza el número total de habitaciones de las viviendas alquiladas, se puede observar que no hay una mayoría absoluta de alguno de 
los tipos, siendo que predominan las viviendas alquiladas con tres habitaciones o piezas ${ }^{7}$, con un $38 \%$.

Sin embargo, no debe dejarse de lado que $23 \%$ de viviendas en alquiler cuentan con una sola habitación, debiéndose encontrar en este grupo el alquiler de cuartos (considerados por el INEI como departamento en edificio). Es necesario anotar también que por el número de habitaciones se puede inferir que los alquileres están dominados por los llamados «minidepartamentos», ya que las viviendas de una y dos habitaciones representan el $45 \%$ de unidades habitacionales en alquiler.

\section{Gráfico 3. Distritos BUV 13: número total de habitaciones de las viviendas} en alquiler, 2016

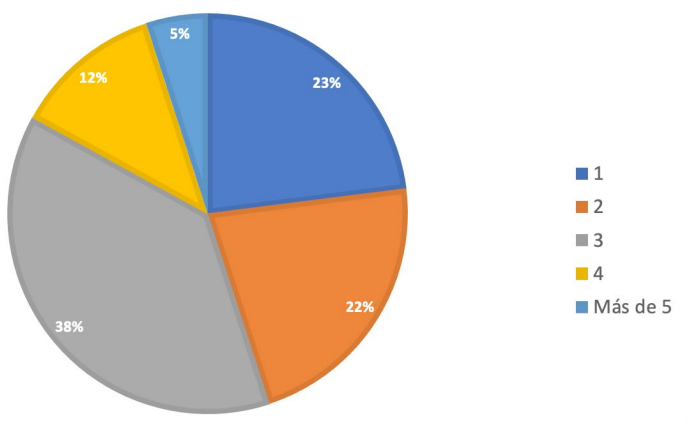

Fuente: INEI-Enaho Anual 2016. Elaboración del autor.

Respecto a la calidad de la vivienda, se ha tomado en cuenta el criterio de «vivienda adecuada» del INEI, por el cual una vivienda presenta «condiciones aceptables, en cuanto a habitabilidad, privacidad y confort». Esta es una estimación que realiza dicha institución y los datos muestran una gran diferencia a favor de las viviendas en alquiler, en donde las viviendas inadecuadas apenas representan el $1 \%$. Un porcentaje menor incluso que el promedio de distritos BUV 13, donde las viviendas inadecuadas representan el 3\%.

Por otro lado, si tomamos en cuenta que las viviendas propias sin título de propiedad son mayoritarias en asentamientos no consolidados, se puede advertir que existe una mayor proporción de viviendas inadecuadas en estos asentamientos que en aquellos que son consolidados.

7 Una habitación o pieza es «el espacio situado en una vivienda, cerrado por paredes que se elevan generalmente, desde el piso hasta el techo y que tiene por lo menos una superficie para dar cabida a la cama de una persona adulta» (INEI). Por esto, no pueden ser entendidas como dormitorios exclusivos. 
Gráfico 4. Distritos BUV 13: calidad de la vivienda por tipo de tenencia, 2016

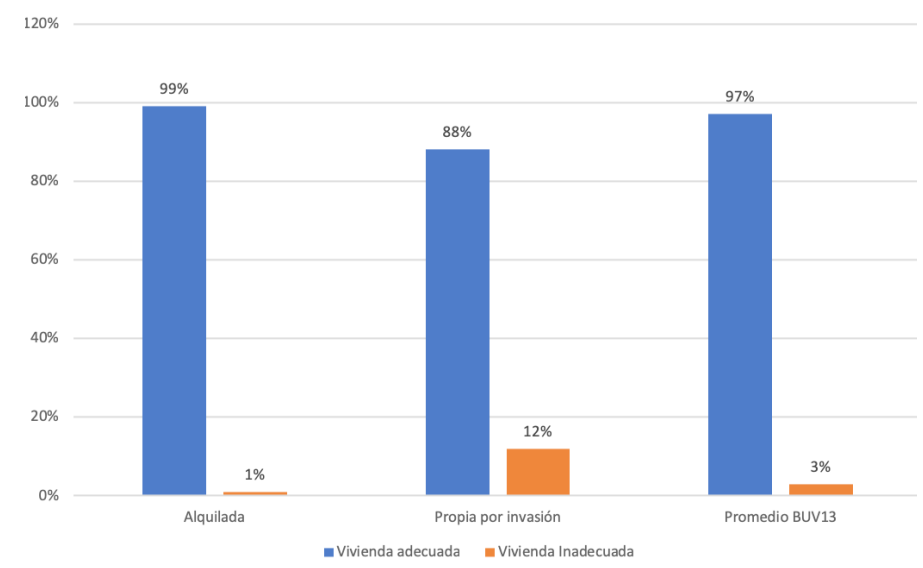

Fuente: INEI-Enaho Anual 2016. Elaboración del autor.

Sin embargo, en términos de hacinamiento, la relación es inversa, siendo el porcentaje de viviendas con hacinamiento para las viviendas en alquiler mayor $(8 \%)$ frente a las propias por invasión (5\%). Pese a esto, la diferencia no es significativa entre una y otra (apenas tres puntos porcentuales).

Por eso, aunque el INEI pueda subestimar la medición del hacinamiento ${ }^{8}$, se considera que este no es un problema acuciante para las viviendas en alquiler. Sin embargo, es necesario considerar que estos barrios podrían ser generadores de hacinamiento en el futuro, en la medida que se acentúe la presencia de minidepartamentos y sobre todo que el alquiler de cuartos muestre un crecimiento en los próximos años.

\subsection{La evolución del precio del alquiler}

Finalmente, respecto al precio del alquiler, la información oficial no dispone de data que permita observar la evolución del precio por $\mathrm{m}^{2}$. De manera que, ante esta imposibilidad, se optó por recoger el monto mensual por alquiler de la Enaho (data anual) desde 2008 hasta 2016 para estos distritos.

Lo primero que llama la atención es el crecimiento progresivo del costo mensual del alquiler, ya que casi se ha duplicado, pasando de S/ 220,00 a S/ 427,00. Asimismo, se debe anotar un aumento del monto promedio mensual

\footnotetext{
8 Se debe precisar que el INEI considera que una vivienda puede servir de alojamiento a un máximo de cinco hogares.
} 
del alquiler entre la provincia de Lima y de los distritos BUV 13. Dicha brecha aumentó sobre todo desde el año 2013, como se muestra en el Gráfico 2.

Asimismo, si se tiene en cuenta que en estos trece distritos los grupos socioeconómicos mayoritarios son el C y D, podríamos estimar que al año 2016, el monto mensual destinado a alquiler representaba en promedio entre $12,3 \%$ y $15 \%$ del ingreso familiar mensual (Asociación Peruana de Empresas de Investigación de Mercados - Apeim, 2016).

Gráfico 5. Distritos BUV 13: condición de hacinamiento por tipo de tenencia, 2016

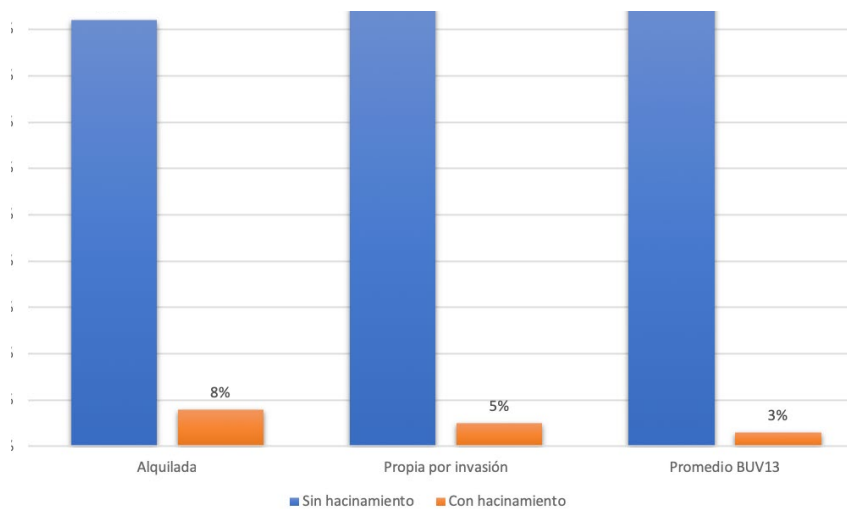

Fuente: INEI-ENAHO Anual 2016. Elaboración del autor.

Gráfico 6. Distritos BUV 13: Evolución del monto mensual (S/) destinado al alquiler, 2008-2016

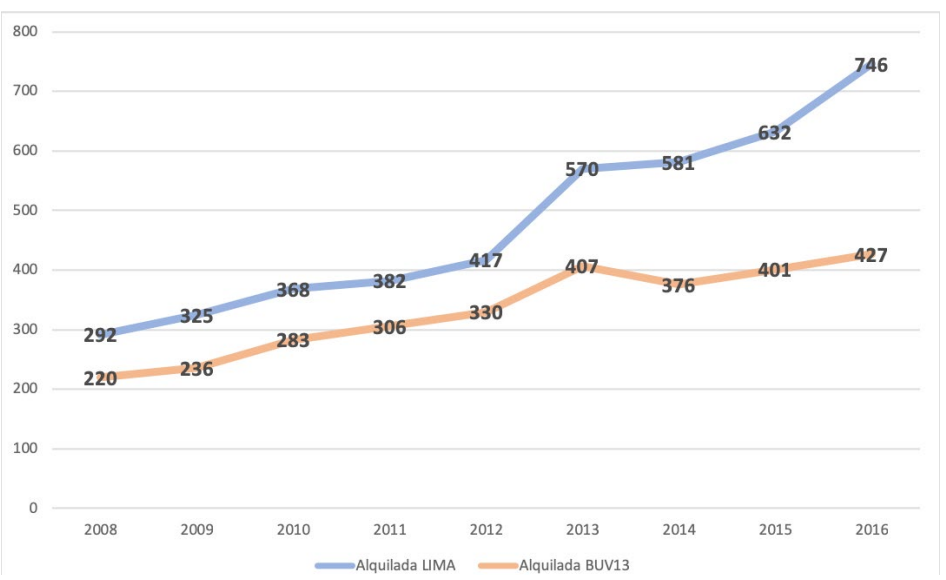

Fuente: INEI-ENAHO Anual 2008-2016. Elaboración del autor. 


\section{DisCUSIONES TEÓRICAS EN TORNO A LAS PREFERENCIAS LOCACIONALES DE LA DEMANDA}

La última parte del artículo busca proponer algunas dimensiones de análisis de las viviendas en alquiler, a partir de los casos de estudio de una investigación en curso en Villa María del Triunfo. Más que la presentación de resultados preliminares, seguimos la orientación metodológica de Becker, para quien los casos nos permiten extraer dimensiones pertinentes de análisis que alimenten razonamientos o discusiones teóricas (Becker, 2016).

\subsection{Preferencias locacionales}

Una primera discusión tiene que ver con la casi nula alusión a las preferencias locacionales de los sectores populares en la investigación urbana, como si este sector poblacional no tuviera criterios o reflexiones de elección. Una explicación se debe a que el estudio de la barriada y el hábitat popular privilegió el derecho a la vivienda y los enfoques colectivistas (barrios, movimientos de pobladores, movimientos sociales urbanos), antes que el acercamiento a escala de los individuos, que permita dar cuenta de la reflexividad de las familias.

Si revisamos la literatura sobre mercados de alquiler, se señala que una parte importante de las preferencias locacionales, determinante del precio del alquiler, está conformada por una externalidad endógena llamada «economía de solidaridad» (Abramo, 2012). Bajo esta idea, las preferencias locacionales de la demanda privilegiarían el acceso a estas redes de apoyo comunitario que los asentamientos consolidados ofrecen.

Sin embargo, es problemático hablar de una economía comunitaria con lógicas de cohesión relativamente fuertes. De hecho, creemos que esta externalidad mitifica una idea de comunidad migrante que mantiene lazos de solidaridad estables al momento de su inserción en la capital, sobre todo porque supone relaciones cara a cara duraderas y más o menos circunscritas al espacio local.

Esto no parece ser la regla en los asentamientos consolidados, menos cuando estos se hallan en contextos de metropolización (Vega-Centeno, 2004), donde los residentes de dichos barrios realizan sus actividades cotidianas, como trabajo, estudio y recreación, fuera de sus localidades.

Por ello, conviene que la investigación urbana discuta este paradigma de comunidad y desarrolle investigaciones que tengan en cuenta los procesos de individualización. Asimismo, la economía de solidaridad puede tener más importancia al momento de decidir dejar un barrio - ya que podría perderse 
un tejido de relaciones vecinales construido en el tiempo de permanenciaque al momento de decidir ingresar a uno.

Por otro lado, en nuestras entrevistas ${ }^{9}$ encontramos una importante reflexión acerca de la elección de una vivienda por razones de localización. Esto significa que tan o más importante que el estado físico de la vivienda, es la ubicación del barrio en relación con la cercanía a los puestos de trabajo, una mejor conectividad con el resto de la ciudad y el acceso a servicios locales.

Básicamente esto es más accesible al trasporte. Por ejemplo, las invasiones están muy lejos. A veces hay escaleras que hay que subir, las personas mayores no pueden subir (Señora en el barrio de Nueva Esperanza).

Este lugar, por lo menos Nueva Esperanza, está progresando económicamente, y se están poniendo caras las viviendas, se está volviendo más comercial. Básicamente porque hay un Real Plaza que lo han puesto hace un año y el hospital Kaelin que es un seguro médico. Toda esta avenida ha ido creciendo, hay restaurantes, espacios de diversión, tenemos un minimarket afiliado a Plaza Vea, es por eso que los espacios aquí son caros, el alquiler ha subido (Joven en barrio de Nueva Esperanza).

De esto se desprende que una dimensión de análisis de las preferencias locacionales es justamente la formación de una jerarquía de barrios en los sectores populares, de la cual el mercado del alquiler se beneficia.

Esto no es una novedad para el resto de América Latina, pero sí para la investigación urbana en Lima. Es pertinente, por ello, conocer a futuro cuáles son los procesos a escala de la estructura urbana que explican la configuración de esta jerarquía: es decir, un barrio gozaría de mayor jerarquía que otro por: ¿su cercanía a la red de transporte público no convencional como Línea 1, Metropolitano?, ¿̇la inversión pública en equipamientos e infraestructura?, ¿la inversión privada que crea centralidades o ejes comerciales?, ¿o también su cercanía a los subcentros laborales, tanto formales como informales?

Es importante generar análisis que pongan en relación las preferencias locacionales con lo que ocurre en la estructura urbana de los distritos con asentamientos consolidados.

\footnotetext{
9 Estas entrevistas se desarrollaron durante febrero y marzo de 2018. Se seleccionaron dos asentamientos populares consolidados del sur de Lima: José Gálvez y Nueva Esperanza en el distrito de Villa María del Triunfo. El primero por ser una «ocupación gradual» de la década de 1950 y el segundo por tratarse de una «invasión» de la misma década. Las entrevistas fueron realizadas a jefes y/o jefas de familia con más de dos años de residencia como inquilinos.
} 


\subsection{Alquiler y seguridad de la tenencia}

Por otro lado, existe otra dimensión que cobra relevancia en los testimonios de nuestros entrevistados cuando se pregunta directamente por qué se elige el alquiler frente a la invasión o compra de terrenos.

En ese sentido, se viene encontrando en los inquilinos un discurso que indica una menor y casi nula predisposición a asumir el «costo del lote» en un asentamiento no consolidado, tanto si es por invasión o mediante la compra de terrenos.

Por invasión porque los terrenos son tan alejados, en zonas de alto riesgo y carentes de servicios, que en un contexto en donde los asentamientos consolidados tienen un stock de viviendas más o menos adecuadas, el costo de oportunidad de ocupar un lote vacío es mayor.

En efecto, la vivienda en alquiler cuenta con todos los servicios básicos y los inquilinos no están dispuestos a vivir en lotes precarios, por lo que estaríamos ante un nuevo perfil de residentes, con mayor reflexividad sobre la localización de las viviendas, que las futuras investigaciones deberán caracterizar mejor.

Asimismo, tan importante como la localización es la consideración que el submercado de loteos viene adquiriendo formas delictivas a través de lo que se conoce como tráfico de terrenos. Lo cual tendría como consecuencia una mayor disposición hacia el alquiler por razones de seguridad, ya que las familias no estarían dispuestas a asumir el coste de la compra de lotes en un entorno hostil, como se colige del siguiente fragmento:

Señora: En una oportunidad, hace años cuando mi hijo estaba más pequeńo, pensamos invadir, por acá, esto que ha sido invasión, allí yo iba a agarrar. Pero mi esposo decía que iba a tener que empezar desde cero, porque la gente ha sufrido cuando ha venido a invadir. Tenía que estar en pleitos porque venían y te querían sacar.

Entrevistador: ¿Quiénes la querían sacar?

Señora: Los hombres que decían que esto les pertenecía a los Gómez ${ }^{10}$, y ellos mandaban a gente, matones, que te agredían. Yo tenía a mi hijo pequeño y no quería pasar esas cosas.

Entrevistador: ¿Los Gómez?, ¿quiénes son?

Señora: Los Gómez son una familia que dicen que eso les pertenece. Y que dicen que están en juicio, por eso que la mayoría de los de arriba no tienen su propiedad en regla. No pueden sacar el agua ni el desagüe todavía (Señora en el barrio de José Gálvez).

${ }_{10}$ La referencia original del apellido ha sido cambiada. 
Hay que recordar que el mercado informal, aunque no esté regulado por las instituciones públicas, sí cuenta con formas de regulación social. Lo que quiere decir que el mercado de loteos ha construido «instituciones informales» (Abramo, 2012) que utilizan mecanismos e instrumentos para garantizar su equilibrio. En ese sentido, lo que nuestras entrevistas revelan es que estos mecanismos de regulación vienen adoptando formas ilegales de actuación como las estafas, y hasta violentas como las extorsiones y amenazas (los «matones»).

Por ello, creemos que otra de las dimensiones de investigación sobre el alquiler debe apuntar a entender una forma particular de «seguridad de la tenencia». Este fue un debate de la década de 1970 promovido, entre otros, por John F.C. Turner y que conviene traer a colación.

Para este autor bastaba la garantía de la posesión de facto, antes que la posesión de jure (Turner y Fichter, 1976), para que los sectores de bajos ingresos construyan progresivamente su vivienda. Es decir, bastaba con que el Estado otorgue garantías de que a la ocupación de los terrenos (seguridad de tenencia) mediante, no le seguirá un desalojo. Una forma que tenía el Estado de garantizar la tenencia era, por ejemplo, la dación de servicios básicos, antes que el reconocimiento jurídico como propietarios (el título de propiedad).

El argumento que queremos señalar es que un contexto donde el tráfico de terrenos viene eliminando las garantías de la posesión de facto contribuye a una mayor predisposición al alquiler, ya que este ofrece mayores garantías de permanencia (seguridad de tenencia) para los residentes.

Esto es comprensible ya que el mercado de alquileres en los asentamientos consolidados tiene mecanismos de regulación particulares, los que van desde contratos escritos entre las partes o el uso de redes de familiares/amigos como respaldo para los inquilinos frente a los arrendatarios, entre otros.

Por esto, aunque se pueda pensar que dichos mecanismos favorezcan al arrendador, también otorgan un marco de protección a los inquilinos, explicitando reglas, aunque no institucionalizadas, que deben cumplir las partes. Así, es pertinente plantear que, ante un crecimiento de las actividades delictivas e ilegales en el submercado de loteos (vía el tráfico de terrenos), es posible que la evolución de la tenencia en alquiler en los asentamientos consolidados siga en aumento.

\subsection{Expectativas y trayectorias residenciales}

Finalmente, una última dimensión de análisis que ponemos de relieve es el significado que tiene la vivienda en alquiler como parte de las expectativas residenciales de los inquilinos, ya que los entrevistados señalan que a futuro 
desean ser propietarios de una vivienda, aunque no necesariamente en las zonas centrales de la ciudad por los costos comparativamente más altos.

Esto indica que el alquiler no es necesariamente una preferencia final, sino una solución de paso dentro de una trayectoria residencial determinada, que privilegia la vivienda en propiedad. Sin embargo, no se debería llegar a la conclusión simplista de que existe una cultura de la propiedad arraigada y difícil de cambiar, sino que las políticas habitacionales no están ofreciendo soluciones de alquiler que sean atractivas para un sector poblacional que no quiere asumir el «costo del lote».

En ese sentido, es pertinente reflexionar si una parte de la demanda de las viviendas en alquiler es una demanda atrapada entre un submercado de loteos cada vez más hostil y una política de vivienda social fallida. Una demanda que se decanta por el alquiler al no encontrar soluciones habitacionales adecuadas tanto a sus ingresos económicos como a sus expectativas de tener una vivienda más o menos bien localizada.

Creemos que la presencia creciente de inquilinos en asentamientos consolidados los convierte en actores relevantes para la comprensión de las trayectorias residenciales que hoy no necesariamente tienen un destino en la invasión o el mercado de loteos. Al mismo tiempo, abre un campo para la investigación urbana, ya que marca el paso a un segundo esquema de trayectorias residenciales.

De esta manera, en el primer esquema, el que explicaba la ciudad popular antes de 1990, tanto la migración como la formación del hogar generaban las necesidades de vivienda. Aquí, los alojados (por lo general los hijos de los primeros fundadores de los barrios) eran los principales actores de una trayectoria residencial que se decantaba en la ocupación ilegal, generalmente realizada por la población excedente del alojamiento. En este esquema, tal como lo mencionaron Riofrío y Driant (1987), el alquiler era un fenómeno incipiente.

Un segundo esquema de trayectorias residenciales estaría marcado por la presencia cada vez más notoria de inquilinos, y donde las necesidades de vivienda son originadas sobre todo por la formación del hogar, antes que por la migración. En este esquema, tanto el alojamiento con el alquiler son soluciones de paso a una cada vez mayor diversidad de alternativas habitacionales: la ocupación ilegal en asentamientos no consolidados, la compra de un lote en el submercado informal de suelo (tanto en asentamientos consolidados como no consolidados), la compra de una vivienda formal y un alquiler frecuente. 


\section{Conclusiones}

La discusión de la política de vivienda social se centra en la adquisición de una vivienda nueva, como si la tenencia en propiedad fuera la única opción habitacional. Esto no ha tenido resultados para los residentes de los asentamientos consolidados, los mismos que vieron en el alquiler una solución habitacional, el cual ha mostrado un aumento significativo tanto en términos absolutos como relativos.

Ilustración 1. Primer esquema de trayectorias residenciales

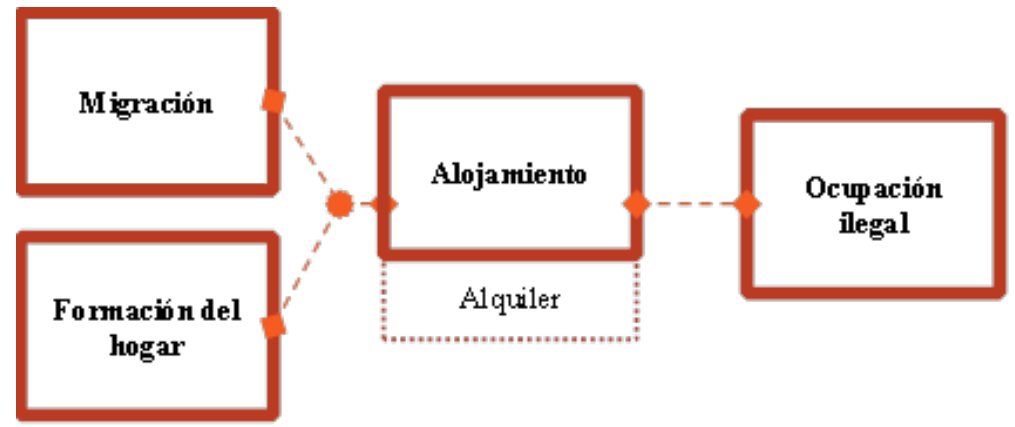

Ilustración 2. Segundo esquema de trayectorias residenciales

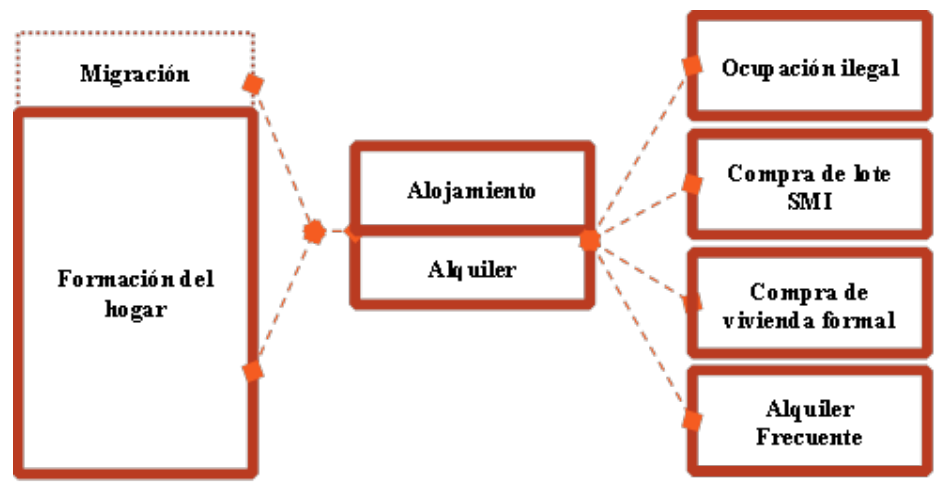

El tipo de vivienda alquilada es sobre todo la casa independiente (62\%) y en segundo término el departamento en edificio (36\%). Asimismo, existe una mayor proporción de minidepartamentos (viviendas de 1 y 2 habitaciones), de los cuales el alquiler de cuartos tiene un peso considerable. 
Asimismo, el 99\% de las viviendas alquiladas son adecuadas para habitar, aunque la proporción de viviendas hacinadas en alquiler en asentamientos consolidados es mayor a las viviendas propias sin título de propiedad en los asentamientos no consolidados.

A pesar de los datos presentados, no consideramos que existan mayores diferencias respecto a la calidad habitacional entre las viviendas en alquiler y las de viviendas en propiedad sin título de propiedad, por lo cual la evolución del alquiler debe explicarse también por las preferencias locacionales de la demanda.

Hemos llamado la atención acerca de algunas de sus dimensiones de análisis: respecto a las preferencias locacionales, consideramos que estas privilegian la ubicación del barrio. Por lo cual debería entenderse que, al mismo tiempo que vivienda, el inquilino en asentamientos consolidados está considerando también pagar por un suelo bien ubicado. Dicha ubicación supone contar con mejor accesibilidad (en tiempo y distancia) a los puestos de trabajo, así como la disponibilidad de servicios locales (públicos o privados).

Al mismo tiempo, hemos destacado que el alquiler estaría ofreciendo una forma particular de seguridad de la tenencia, seguridad de permanencia que el aumento de los mecanismos delictivos del mercado de loteos ya no garantiza.

Seguir investigando estas dimensiones debería servir para el diseño y la evaluación de las políticas habitacionales, en el sentido de saber si los productos que ofrece la política de vivienda satisfacen las expectativas residenciales de los actuales inquilinos y entiende sus lógicas de localización, ya que no basta solo con ofrecer vivienda, sino promover soluciones habitacionales bien localizadas.

Por años, los estudios urbanos en el Perú, específicamente la llamada corriente crítica, reclamaron que la «barriada» no podía seguir siendo una modalidad viable de acceso al suelo y de crecimiento de la ciudad, y que era necesario prohibir activamente las invasiones, al mismo tiempo que el Estado debería ofrecer programas de acceso ordenado al suelo y módulos de vivienda (en propiedad) básicos.

Aceptando que la barriada ya no cumple el rol que tuvo en la década de 1960, y que la expansión por loteos tampoco es sostenible, es importante que la investigación urbana se dirija al alquiler en los asentamientos consolidados, a fin de proponer instrumentos que la promuevan y la regulen, ya que la experiencia nos ha dicho que si se deja hacer, esta solución puede convertirse, como se han convertido las invasiones y el transporte público convencional, en una verdadera pesadilla.

Asimismo, se deben rastrear los nexos entre el submercado de loteos y el de alquileres. En ese sentido, hacer efectivas las sanciones a los traficantes de terrenos 
y, sobre todo, tener tolerancia cero a las invasiones podría conducir con más fuerza a los sectores populares urbanos a la opción del alquiler. Esta no será la solución a los problemas habitaciones, pero permitiría contar con una solución de vivienda con uso intensivo del suelo que promueva una ciudad compacta.

La promoción del alquiler, la estimulación de la asociatividad entre propietarios que eviten las subdivisiones de lotes y la mejora en la información de los precios de este submercado pueden ser los primeros pasos para institucionalizar el alquiler como parte de una política de vivienda para los asentamientos consolidados.

\section{REFERENCIAS}

Abramo, P. (2005). La teoría económica de la favela. Boletin $C F+S$, (29/30). Recuperado de http:// habitat.aq.upm.es/boletin/n29/apabr.html

Abramo, P. (2012). La ciudad com-fusa: mercado y producción de la estructura urbana en las grandes metrópolis latinoamericanas. Revista EURE, Revista de Estudios Urbano Regionales, 38(114). https://doi.org/10.4067/S0250-71612012000200002

Asociación Peruana de Empresas de Investigación de Mercados - Apeim (2016). Niveles socioeconómicos 2016. Lima: ENAHO-APEIM. Recuperado de http://www.apeim.com.pe/wp-content/ themes/apeim/docs/nse/APEIM-NSE-2016.pdf

Artacho, J. D. P. (2014). Sociología de la residencia y residencia móvil: logros teóricos y límites prácticos. Empiria. Revista de metodología de ciencias sociales, O(27), 21-48. https://doi.org/10.5944/ empiria.27.2014.10861

Becker, H. (2016). Mozart, el asesinato y los límites del sentido común. Buenos Aires: Siglo Veintiuno Editores.

Briceño, R. (2010). Libertad para alquilar: El mercado informal de vivienda de Caracas. Territorios, O(18-19). Recuperado de https://revistas.urosario.edu.co/index.php/territorios/article/view/829

Burga, J. (2006). El ocaso de la barriada. Propuestas para la vivienda popular. Lima: MVCS-FAUA.

Calderón, J. (2007). Mercados inmobiliarios en asentamientos informales de Lima y procesos de diferenciación social. Cambridge: Lincoln Institute / INFOmercados.

Calderón, J. (2011). Titulación de la propiedad y mercado de tierras. Revista EURE, Revista de Estudios Urbano Regionales, 37(111). https://doi.org/10.4067/S0250-71612011000200003

Calderón, J. (2016). La ciudad ilegal. Lima en el siglo XX. Lima: Punto Cardinal.

Espinoza, Á. y Fort, R. (2017). Inversión sin planificación: la calidad de la inversión pública en los barrios vulnerables de Lima. Lima: Grade, Grupo de Análisis para el Desarrollo.

Fernandes, E. (2011). Regularización de asentamientos informales en América Latina. Cambridge: Lincoln Institute of Land Policy.

Gonzales de Olarte, E. (2012). Lima, una ciudad policentrica. Un análisis a partir de la localización del empleo. Revista de Investigaciones Regionales, otoño, 29-52. Recuperado de https://investigacionesregionales.org/revista/otono-2012/

Jiménez, E. (2014). Problemas y opciones de acceso a suelo en tiempos de neoliberalismo. Experiencias de ciudades mexicanas. En A. X. Iracheta Cenecorta, C. I. Pedrotti y R. Fernández Wagner (eds.), El suelo urbano en Iberoamérica (pp. 21-41). Zinacantepec, Estado de México: El Colegio Mexiquense, A.C. 
Kemeny, J. (1992). Housing and Social Theory. Londres y Nueva York: Routledge.

Lascoumes, P. y Le Galès, P. (2014). Sociología de la acción pública. México, D.F.: El Colegio de México.

McFarlane, C. (2012). Rethinking Informality: Politics, Crisis, and the City. Planning Theory \& Practice, 13(1), 89-108. https://doi.org/10.1080/14649357.2012.649951

Ministerio de Vivienda, Construcción y Saneamiento (2014). Situación de los barrios urbano marginales en el Perú 2012. Lima: MVCS.

Parias, A. (2010). El mercado de arrendamiento en los barrios informales en Bogotá, un mercado estructural. Territorios, O(18-19). Recuperado de https://revistas.urosario.edu.co/index.php/ territorios/article/view/828

Riofrío, G. y Driant, J.C. (1987). ¿Qué vivienda han construido? Nuevos problemas en viejas barriadas. Lima: Cidap, IFEA, Tarea.

Turner, J. y Fichter, R. (1976). Libertad para construir. México, D.F.: Siglo Veintiuno Editores.

Vega-Centeno, P. (2004). De la barriada a la metropolización. Lima y la teoría urbana en la escena contemporánea. En Desco, Las ciudades en el Perú (pp. 47-70). Lima: Desco.

Ward, P., Jiménez, E. y Di Virgilio, M. (2015). Housing Policy in Latin American Cities: A New Generation of Strategies and Approaches for 2016 UN-HABITAT III. Routledge. https://doi. org/10.4324/9781315773001

Zolezzi, M., Tokeshi, J. y Noriega, C. (2005). Densificación habitacional. Una propuesta de crecimiento para la ciudad popular. Lima: Desco. Programa Urbano. 